\title{
Intention on food safety among food handlers at the beach culinary tourism area
}

\author{
Asep Rustiawan, Dyah Suryani
}

Department of Public Health, Universitas Ahmad Dahlan, Indonesia

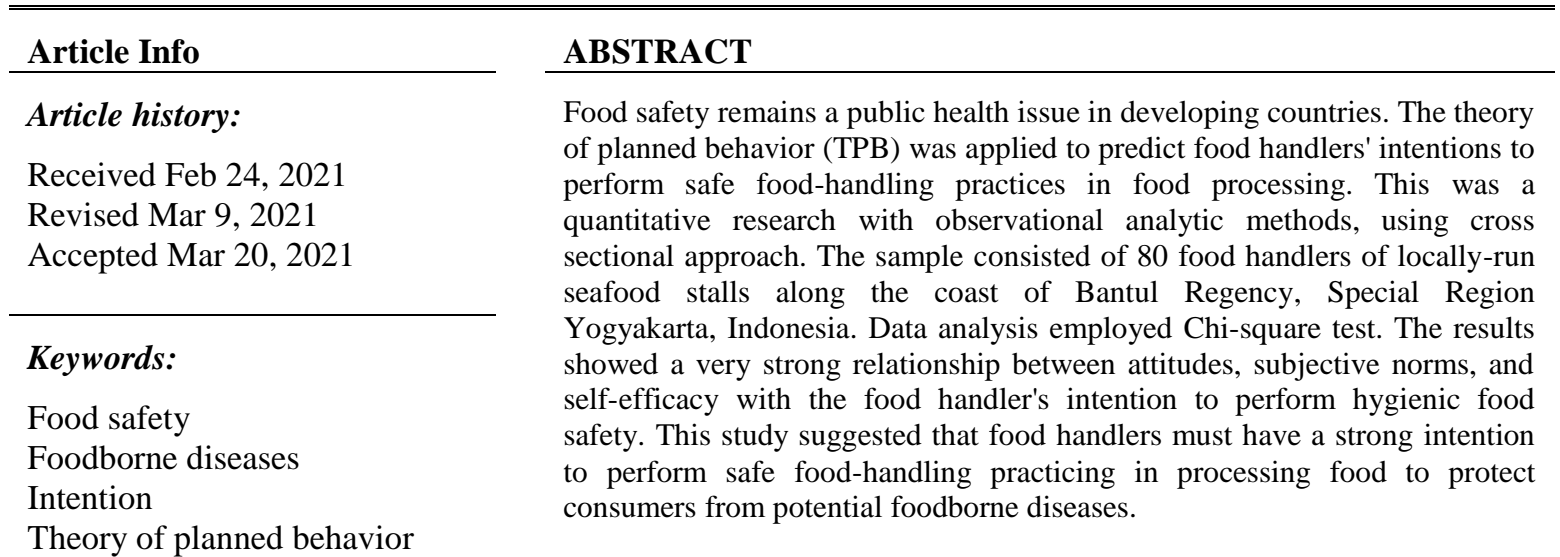

This is an open access article under the CC BY-SA license.

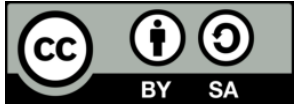

\section{Corresponding Author:}

Dyah Suryani

Department of Public Health

Universitas Ahmad Dahlan

Warungboto, Umbulharjo, Special Region Yogyakarta, 55164, Indonesia

Email: dyah.suryani@ikm.uad.ac.id

\section{INTRODUCTION}

Food safety is still the world's major concern. Millions of people across the world are hospitalized and even die after eating contaminated food every year [1], [2]. Foodborne illness resulting from consuming water or food contaminated with microorganisms or toxins causing severe clinical symptoms, critical cases and even death. Although preventable, foodborne diseases (FBDs) remain a major public health challenge and a vital contributor towards morbidity and mortality worldwide, despite the industries and governments' effort to ensure the hygienic-sanitary quality of food production. Food-borne diseases is a burden to the health care system and harming trade and tourism [3]. Poor sanitation, improper personal hygiene and contaminated utensils as well as untreated water used by street vendors in developing countries, all act as a conduit for transmission of pathogens via foods to humans [4]. Food handlers are individuals who are responsible for handling food and play a vital role in providing hygienic food [5]. Food handlers must ensure food safety and prevent food contamination throughout the production chain all the way from preparation of food, storing, cooking and serving [6], therefore it is very important for food safety during food service [7]. The behavior of healthy food processing begins with the intention to perform safe food-handling practices. The intention to behave of a food handler is influenced by internal factors from within as well as external factors from his environment. The strength of the intention to act is assumed to be a motivational factor that influences behavior and is an indication of how a person will put in to perform the behavior.

In theory of planned behavior (TPB), behavior is determined by intention which is influenced by attitudes, subjective norms, and self-efficacy [8]. Attitudes are defined as the people's evaluation of a particular entity with some degree of favor and disfavor. Meanwhile, subjective norms are social factors that 
represent the social pressure to perform or not perform the behavior, and self-efficacy is the individual's belief in the ability to perform the behavior. The low intention reflects the negative attitude, low belief and social support towards the importance of safe food-handling practices in food processing.

Tourist visits to the beach culinary tourism destination of Bantul Regency, Special Region of Yogyakarta (DIY) continue to increase every year. The number of visits in 2006 were just 800,000 and it hit 3.67 million in 2018 [9]. The increase in the number of tourist visits has a broad impact on aspects of the socio-economic life of the community, such as increasing employment in the food and service sector. At the beginning of 2019, nearly 100 locally-run food stalls were operating around Depok beach. These locally-run food stalls have various levels of development, some are large, and medium, but some are still small. The locally-run food stall business on Depok beach is part of an organization "Koperasi Mina Bahari 45 Pantai Depok", which provides food and services to process food items brought by consumers into ready-to-eat food.

The research findings of previous research [10], which were conducted by using the guidelines of Permenkes RI No. 1096/MENKES/PER/VI/2011 on Hygiene and Sanitation for Food Services (Higiene Sanitasi Jasa Boga), it was found that more than $60 \%$ of the facilities and infrastructure of the locally-run food stalls did not meet the requirements, more than $60 \%$ of food processing methods did not meet the requirements. In addition, there were $30 \%$ of samples of grilled fish contained Eschericia coli bacteria and most importantly more than $80 \%$ of food processors did not meet the requirements. The purpose of this study was to determine the factors associated with food handlers' intention to perform safe food-handling practices based on Theory of Planned Behavior.

\section{RESEARCH METHOD}

This was a quantitative research with observational analytic methods conducted by direct observation of respondents. The research design used a cross sectional approach. Respondents in this study were food handlers of locally-run seafood culinary stalls along the coast of Bantul Regency. Samples were taken by total sampling. The independent variables were attitudes, subjective norms and self-efficacy, and the dependent variable was intention in safe food handling practices. The research was conducted with a survey method using a questionnaire with a Likert scale (strongly agree, agree, doubt, disagree and strongly disagree). The attitude questionnaire consisted of nine statements, six statements of subjective norms, eight statements of self-efficacy and nine statements of intention. The questionnaire has been validated through validity and reliability testing using a sample of 32 food handlers from locally-run seafood culinary stalls along the coast of Kulon Progo Regency, Indonesia. The results of the validation test obtained Cronbach's Alpha value of 0.896 . The research data were categorized using the median, and analyzed using the Chisquare test. This research has received ethical approval: KEP UAD no. 012010064.

\section{RESULTS AND DISCUSSION}

Respondents were food handlers of locally-run culinary stalls that carry out food processing. The number of respondents was 80 food handlers. The characteristics of the respondents include age, education level and origin of beach location, which are presented in the frequency distribution in Table 1.

Table 1 shows that based on the age category, the number of respondents was quite evenly distributed with the most number in later adulthood age group of 27 people $(33.75 \%)$. The most number of education level is secondary level of 45 people or $56.25 \%$. The most number of respondents come from Depok Beach of 26 people $(32.50 \%)$. Table 2 displays the univariate analysis of the independent and dependent variables.

Table 2 shows that $50 \%$ or 40 respondents have a positive attitude towards the intention to carry out safe food handling practices. There were 44 respondents $(55 \%)$ had high subjective norms or social support for the intention to perform safe food-handling practices, 45 respondents $(56.25 \%)$ had high selfefficacy/ability to intend to perform safe food-handling practices. Also, respondents who have a strong intention to perform safe food handling practices were 41 people or $51.25 \%$. The results of the Chi-square test are displayed in Table 3.

Table 3 shows that there is strong relationship between attitudes, subjective norms and self-efficacy with the intention to perform safe food-handling practices. The p-value (0.00) obtained is smaller than the significance level (0.01). 
Table 1. Respondents' age, education level and origin of beach location

\begin{tabular}{lcc}
\hline \multicolumn{1}{c}{ Category } & Frequency (person) & Percentage (\%) \\
\hline Age (Year) & & \\
Later adolescent & 7 & 8.75 \\
(17-25 Years) & & \\
Early Adulthood & 20 & 25.00 \\
(26-35 Years) & & \\
Later Adulthood & 27 & 33.75 \\
(36-45 Years) & & \\
Early Elderly & 26 & 32.50 \\
(46-55 Years) & & \\
Education level & & \\
Secondary Level & 45 & 56.25 \\
High Schol/Vocational & 34 & 42.50 \\
Diploma & 1 & 1.25 \\
Origin of beach location & & \\
Baru & 22 & 27.50 \\
Depok & 26 & 32.50 \\
Goa Cemara & 5 & 6.25 \\
Kuwaru & 6 & 7.50 \\
Parangtritis & 19 & 23.75 \\
Samas & 2 & 2.50 \\
Total & 80 & 100 \\
\hline Source: Primary Data, 2020 & &
\end{tabular}

Table 2. Respondents' attitudes, subjective norms, self-efficacy and intention to perform safe food-handling

\begin{tabular}{lcc}
\multicolumn{3}{c}{ practices } \\
\hline Category & Frequency (person) & Percentage (\%) \\
\hline Attitude & & \\
Positive & 40 & 50.00 \\
Negative & 40 & 50.00 \\
Subjective norm & & \\
High & 44 & 55.00 \\
Low & 36 & 45.00 \\
Self-efficacy & & \\
High & 45 & 56.25 \\
Low & 35 & 43.75 \\
Intention & & \\
Strong & 41 & 51.25 \\
Weak & 39 & 48.75 \\
\hline Total & 80 & 100 \\
\hline Source: Primary Data, 2020 &
\end{tabular}

Table 3. The relationship between variables

\begin{tabular}{|c|c|c|c|c|c|c|c|}
\hline \multirow{3}{*}{ Variable } & \multicolumn{4}{|c|}{ Intention } & \multirow{3}{*}{ p-value } & \multirow{3}{*}{$\mathrm{RP}$} & \multirow{3}{*}{ CI $99 \%$} \\
\hline & \multicolumn{2}{|c|}{ Weak } & \multicolumn{2}{|c|}{ Strong } & & & \\
\hline & $\mathrm{n}$ & $\%$ & $\mathrm{n}$ & $\%$ & & & \\
\hline \multicolumn{8}{|l|}{ Attitude } \\
\hline Negative & 29 & 36.25 & 11 & 13.75 & \multirow{2}{*}{0.00} & \multirow{2}{*}{2.90} & \multirow{2}{*}{$1.53-8.89$} \\
\hline Positive & 10 & 12.50 & 30 & 37.50 & & & \\
\hline \multicolumn{8}{|c|}{ Subjective norm } \\
\hline Low & 34 & 42.50 & 2 & 2.50 & \multirow{2}{*}{0.00} & \multirow{2}{*}{8.31} & \multirow{2}{*}{$3.89-43.29$} \\
\hline High & 5 & 6.25 & 39 & 48.75 & & & \\
\hline \multicolumn{8}{|c|}{ Self-efficacy } \\
\hline Low & 31 & 38.75 & 4 & 5 & \multirow{2}{*}{0.00} & \multirow{2}{*}{4.98} & \multirow{2}{*}{$2.64-19.28$} \\
\hline High & 8 & 10 & 37 & 46.25 & & & \\
\hline
\end{tabular}

\subsection{Attitude the relationship between the attitude and the intention to perform safe food handling} practices

Attitudes toward behavior are determined by individual beliefs about the consequences of behavior and their evaluation of these behaviors [11]. Belief is obtained from the results of an individual's subjective assessment by connecting certain behaviors with various benefits or losses that might be obtained if the individual does or does not do it. This belief is also influenced by the breadth or narrowness of knowledge 
and the life experience. Evaluation of behavior is obtained based on the belief that whether carrying out the behavior is pleasant or unpleasant for them. Thus, the attitude of liking or disliking on safe food-handling practices will be determined by the food handler's own belief and the feeling of satisfaction or pleasure when implementing safe food-handling practices during food processing.

The results of the data analysis show that the attitude of food handlers towards safe food-handling practices is closely related to their intention to behave. On the other hand, the univariate data description shows that the number of food handlers who have negative attitudes of $50 \%$, while the prevalence ratio (RP) value is 2.90 with a CI value of $99 \%=1.53-8.89$ which does not include the number one. The meaning of the RP value is that food handlers who have a negative attitude are 2.90 times more likely to have a weak intention to perform safe food-handling practices as compared to food handlers who have a positive attitude. Thus, it is important to increase the number of food handlers who have a positive attitude by organizing various training related to safe food-handling to improve their knowledge and skills.

With the increase in knowledge and skills, it will improve the belief which encourages the growth of a strong intention among food handlers to carry out safe food-handling practices in food processing [12]. The combination of positive behavior, positive attitude, and education of food handlers is needed to improve safe food-handling practices [13]. High enthusiasm for attitudes supported by subjective norms will result in greater self-efficacy which leads to a stronger intention to perform safe food-handling practices [14]. This study is in line with previous research which stated that the majority of respondents showed positive attitudes towards safe food-handling practices with an overall score of $83.7 \%$ [15]. The reduction in the incidence of food borne diseases is strongly influenced by the attitude of food handlers towards implementing the food safety plan [16].

\subsection{The relationship of subjective norms with the intention to perform safe food-handling practices}

Subjective norms are defined as a person's perception that most people who are important to him (significant other) that he should do something or not [17]. In the context of food handlers at Bantul beach tourism culinary stalls, social figures who might be considered important are community health center officers, koperasi officers or fellow food handlers. A food handler who believes that community health center officers, koperasi officers or fellow food handlers expect him to perform safe food-handling practices, and then already has had normative beliefs. If this negative belief is supported by a strong motivation to do so, then these food handlers have already had high subjective norms which will encourage the growth of a strong intention to carry out safe food-handling practices in food processing.

The results of the bivariate test concluded that subjective norms have a very close relationship with the intention to perform safe food-handling practices among food handlers of Bantul beach. This means that the support of local people, including the role of stake holders, is very influential in the growth of intention among food handlers. The greater the support given, the stronger the intention is formed. Subjective norms are perceptions that come from individuals on social pressure from their environment to perform or not perform considered practices, and are related to perceived normative decisions from behavior [18].

Univariate analysis data in Table 2 shows that the number of food handlers who have low subjective norms reaching $45 \%$. In addition, the bivariate analysis data in Table 3 shows the prevalence ratio (RP) value of 8.31 with a $99 \%$ CI value $=3.89-43.29$ which does not include the number 1 . The meaning of the RP value is food handlers who have low belief and subjective norms are 8.31 times more likely to have weak intentions to perform safe food-handling practices than those with high subjective norm beliefs. In this regard, the role of stakeholders and the support of fellow food handlers are needed to foster high subjective norm belief among food handlers, which will encourage the growth of a strong intention in within to perform safe food-handling practices in processing food. This research is in line with previous research which stated that subjective norms had a strong influence on safe food-handling intentions [19].

\subsection{The relationship between self-efficacy and the intention to perform safe food-handling practices}

Self-efficacy or behavior control is an individual's perception on how easy or difficult it is to manifest a particular behavior [20]. Self-efficacy in a food handler is determined by two aspects including control over behavior (control factors) in the availability of supporting resources, as well as belief in one's ability to perform safe food-handling practices with the help of these resources (belief in the influence of the control factor).

The stronger the belief in the availability of resources and opportunities that are owned, the greater the belief in the influence of these resources in supporting behavior, and the higher the self-efficacy they have. Food handlers who have adequate resources such as cooking utensils, clean water, refrigerators, watertight kitchen, and supporting competencies, will have high belief in their abilities so that they will be more motivated and strive to carry out safe food-handling practices in processing food because they believe that with the available resources and opportunities, the difficulties they face will be able to be overcome. 
Self-efficacy is a person's belief in the ability to complete a job or behavior. In other words, the individual motivation is more based on what they believe than on an objective assessment [21]. The self-efficacy of a person is also influenced by the breadth and narrowness of his knowledge and education.

Previous research has shown that high self-efficacy is a strong indicator for individuals to adopt and maintain positive health behaviors and refrain from doing negative health behaviors [22]. Other studies suggested that self-efficacy scores were high, indicating that participants had a high level of confidence in their ability to handle food safely and properly. In addition, those at higher stages tended to have significantly greater self-efficacy scores than those at lower stages [23]. High self-efficacy will affect a person's belief to be able to complete certain tasks given and it also affects the level of effort and persistence of a person to complete difficult tasks.

The bivariate analysis in this study concluded that the food handler's self-efficacy is closely related to the intention to perform safe food-handling practices. In addition, a Prevalence Ratio (RP) was obtained of 4.98 with a CI value of $99 \%=2.64-19.28$ which does not include the number 1.The meaning of the RP value is that food handlers who have low self-efficacy have a chance of 4.98 times more likely to have weak intentions than food handlers with high self-efficacy. In other words, food handlers with high selfefficacy will have a strong intention to perform safe food-handling practices in food processing.

Based on the data in Table 2, it is known that $43.75 \%$ of food handlers have low self-efficacy. The greater number of food handlers who have low self-efficacy can be caused the level of education of food handlers is still relatively low (secondary level) (56.25\%). In previous [24] research the educational status was identified as the factors having a stronger significant association with the food safety practice. In addition, based on the results of field observations it is known that the availability of cooking infrastructure and facility is still limited, which is reflected in the low ownership of the refrigerator, the kitchen floor is still ground floor and the limited facilities for clean water and garbage disposal. Because previous research states that the adequacy of buildings and facilities is positively related to food safety practices [25]. Low levels of education and limited availability of supporting resource can lead to low self-efficacy in the form of a loss of self-confidence so that you feel unable to carry out safe food-handling practices in food processing. In connection with the above facts, efforts to increase the self-efficacy among food handlers are important. These efforts can be carried out in the form of training to improve knowledge and skills on safe foodhandling as well as the provision of various adequate supporting facilities. In accordance with previous research which states that health education and promotion of hygiene [26] for food handlers is important to increase knowledge and practices related to hygiene in the prevention and control of foodborne diseases [27], [28]. Refreshment training and its relatively short duration remain important for improving food safety behavior among foodservice workers [29]. The support and positive reinforcement and motivation provided to food handlers by supervisors, managers, and health workers are essential for the successful improvement of food safety practices [30].

\section{CONCLUSION}

There are very significant relationships between attitudes, subjective norms, and self-efficacy and the intention towards safe food-handling practices. Food handlers should have strong intention to carry out safe food-handling practices in processing food so that consumers of culinary tourism in Bantul Regency are safe from foodborne diseases. There will be the need of guidance for food handlers through various training in the field of safe food-handling practices, support from stakeholders and the provision of infrastructure for processing adequate food to ensure the implementation of safe food-handling practices and ensuring consumers are safe from food borne diseases in the tourist area. This study has the limitation which only involves a small number of food handlers because most of the culinary stalls are still closed due to the pandemic. However, this study is exploratory and serves as a pilot study for further research on factors related to safe food-handling practices in tourist areas. Further research is suggested to involve larger numbers of food handlers and collaborate with the government so that it can establish a more comprehensive approach to ensure safe food-handling practices in food processing.

\section{REFERENCES}

[1] WHO, "World Health Day 2015 Campaign tool kit," pp. 1-12, 2015.

[2] F. Fung, H. S. Wang, and S. Menon, "Food safety in the 21st century," Biomedical Journal, vol. 41, no. 2, pp. 8895, 2018.

[3] WHO, "Strategic Plan for Food Safety," Organ. Mund. da Saúde, pp. 1-31, 2013.

[4] S. N. Onyeneho and C. W. Hedberg, "An assessment of food safety needs of restaurants in Owerri, Imo State, Nigeria," International Journal of Environmental Research and Public Health, vol. 10, no. 8, pp. 3296-3309, 2013, doi: 10.3390/ijerph10083296. 
[5] S. Phillip and E. Anita, "Efficacy of the theory of planned behaviour model in predicting safe food handling practices," Food Control, vol. 21, no. 7, pp. 983-987, 2010, https://doi.org/10.1016/j.foodcont.2009.12.012.

[6] H. K. Lee, H. Abdul Halim, K. L. Thong, and L. C. Chai, "Assessment of food safety knowledge, attitude, selfreported practices, and microbiological hand hygiene of food handlers," Int. J. Environ. Res. Public Health, vol. 14, no. 1, PP. 1-14, 2017, doi: 10.3390/ijerph14010055.

[7] L. M. Zanin, D. T. da Cunha, V. V. de Rosso, V. D. Capriles, and E. Stedefeldt, "Knowledge, attitudes and practices of food handlers in food safety: An integrative review," Food Research International, vol. 100, no. July, pp. 53-62, 2017.

[8] I. Ajzen, "Consumer attitudes and behavior: the theory of planned behavior applied to food consumption decisions," Italian Review of Agricultural Economics, vol. 70, no. 2, pp. 121-138, 2015.

[9] Department of Tourism, "DIY Tourism Statistics/Statistik Pariwisata DIY," 2018.

[10] D. Suryani, "The existence of the number of grilled pomfret fish germs and grilled tableware/Keberadaan Angka Kuman Ikan Bawal Bakar dan Peralatan Makan Bakar," Jurnal Kesehatan Masyarakat, vol. 9, no. 2, pp. 191-196, 2014, doi: https://doi.org/10.15294/kemas.v9i2.2848.

[11] I. Ajzen, "The theory of planned behavior," Organizational Behavior and Human Decision Processes, vol. 50, no. 2, pp. 179-211, 1991, doi: https://doi.org/10.1016/0749-5978(91)90020-T.

[12] M. A. K. A. K. Bin Rohin, "Knowledge, attitudes and practices (KAP) on good manufacturing practices (GMP) among food handlers in Terengganu hospitals," International Journal of Pharmacy and Pharmaceutical Sciences, vol. 8, no. 11, pp. 53-59, 2016, doi: 10.22159/ijpps.2016v8i11.13000.

[13] W. H. Ko, "The relationship among food safety knowledge, attitudes and self-reported HACCP practices in restaurant employees," Food Control, vol. 29, no. 1, pp. 192-197, 2013.

[14] M. A. Shapiro, N. Porticella, L. C. Jiang, and R. B. Gravani, "Predicting intentions to adopt safe home food handling practices. Applying the theory of planned behavior," Appetite, vol. 56, no. 1, pp. 96-103, 2011.

[15] C. Bou-Mitri, D. Mahmoud, N. El Gerges, and M. A. Jaoude, "Food safety knowledge, attitudes and practices of food handlers in lebanese hospitals: A cross-sectional study," Food Control, vol. 94, no. June, pp. 78-84, 2018, doi: https://doi.org/10.1016/j.foodcont.2018.06.032.

[16] F. Akabanda, E. H. Hlortsi, and J. Owusu-Kwarteng, "Food safety knowledge, attitudes and practices of institutional food-handlers in Ghana," BMC Public Health, vol. 17, no. 1, pp. 1-9, 2017.

[17] I. Ajzen, Action Control, Springer-Verlag Berlin Heidelberg, 1985, pp. 11-39.

[18] W. A. Hamilton K., Daniels L., White KM, and Murray M., "Predicting Mothers' Decisions to Introduce Complementary Feeding at 6 Months. An Investigation Using an Extended Theory of Planned Behaviour," vol. 56, pp. 674-681, 2011, doi: 10.1016/j.appet.2011.02.002.

[19] G. E. Ruby, U. F. Ungku Zainal Abidin, S. Lihan, N. N. Jambari, and S. Radu, "Predicting intention on safe food handling among adult consumers: A cross sectional study in Sibu district, Malaysia," Food Control, vol. 106, no. January, 2019, doi:10.1016/J.FOODCONT.2019.06.022.

[20] I. Ajzen, Attitudes, Personality and Behaviour, McGraw-Hill Education (UK), 2005.

[21] A. Bandura, Social Learning Theory, Englewood Cliff, NJ: Prentice Hall, 1977.

[22] A. S. Beavers, J. K. Richards, R. S. McCallum, P. M. Davidson, G. Skolits, and M. Crosby, "Measuring selfefficacy of food safety in middle school populations," Food Protection Trends, vol. 33, no. 3, pp. 127-132, 2013.

[23] C. Byrd-Bredbenner, J. Maurer, V. Wheatley, E. Cottone, and M. Clancy, "Observed food safety behaviours of young adults," British Food Journal, vol. 109, no. 7, pp. 519-530, 2007.

[24] H. Dagne, R. P. Raju, Z. Andualem, T. Hagos, and K. Addis, "Food safety practice and its associated factors among mothers in debarq town, Northwest Ethiopia: Community-based cross-sectional study," BioMed Research International, pp. 1-8, June, 2019, doi: https://doi.org/10.1155/2019/1549131.

[25] D. T. Da Cunha, E. Stedefeldt, and V. V. de Rosso, "The role of theoretical food safety training on Brazilian food handlers' knowledge, attitude and practice," Food Control, vol. 43, pp. 167-174, 2014.

[26] V. Curtis, W. Schmidt, S. Luby, R. Florez, O. Touré, and A. Biran, "Hygiene: New hopes, new horizons," Lancet Infectious Diseases, vol. 11, no. 4, pp. 312-321, 2011.

[27] M. R., L. P., K. P. S., D. M.K., and K. J., "Evaluation of a health education intervention on knowledge and attitudes of food handlers working in a medical college in Delhi, India," Asia-Pacific Journal Public Heath, vol. 20, no. 4, pp. 277-286, 2008.

[28] L. I. Auad, V. C. Ginani, E. Stedefeldt, E. Y. Nakano, A. C. S. Nunes, and R. P. Zandonadi, "Food safety knowledge, attitudes, and practices of brazilian food truck food handlers," Nutrients, vol. 11, no. 8, pp. 1-19, 2019.

[29] H. K. Adesokan, V. O. Akinseye, and G. A. Adesokan, "Food safety training is associated with improved knowledge and behaviours among foodservice establishments workers," International Journal of Food Scienc, pp. $1-9,2015$.

[30] D. Al-Kandari, J. Al-abdeen, and J. Sidhu, "Food safety knowledge, attitudes and practices of food handlers in restaurants in Kuwait," Food Control, vol. 103, no. April, pp. 103-110, 2019. 